\title{
An Atypical Adult Presentation of Acute Clonidine Intoxication: A Case Report
}

\author{
Manna Maria Theresa ${ }^{1}$, Arunkumar $K^{2}$, Gireesh Kumar K P ${ }^{3}$, \\ Sreekrishnan T. $\mathbf{P}^{4}$, Kathyayini V. $\mathbf{R}^{5}$ \\ ${ }^{1,5}$ MD Resident, ${ }^{2,4}$ Assistant Professor, ${ }^{3} \mathrm{HOD}$, \\ Dept of Emergency Medicine, Amrita Institute of Medical Sciences, Kochi, Kerala
}

Corresponding Author: Manna Maria Theresa

\begin{abstract}
Clonidine is drug which was initially used as a nasal decongestant and now commonly used in the treatment of several conditions both in adults and children. Even though there is no minimum toxic dose for this drug, low-dose clonidine poisonings are commonly seen in children. Accidental ingestion of this drug or transdermal exposure can cause altered sensorium, hypertension, hypotension and bradycardia because of various mechanism of action.
\end{abstract}

Keywords: Clonidine, intoxication, hypotension, miosis.

\section{INTRODUCTION}

Clonidine, the drug has a widespread use, such as in the treatment of hypertension, glaucoma, Attention deficit hyperactivity disorder (ADHD) and sleep disturbances in children. ${ }^{[1]}$ It also has usage as a sedative, in Anaesthesia and in opioid detoxification. Clonidine is an imidazoline derivative which acts mainly as a central alpha-2 agonist. ${ }^{[2]}$ A wide variety of medications in the form of Guanfacine and Tizanidine (a muscle relaxant), glaucoma medications like Brimonidine, apraclonidine and Dexmedetomidine (sedative) are available. Bioavailability of this drug is 75100 percent.

\section{CASE PRESENTATION}

A 70 year old gentleman with no known documented comorbidities was brought to the emergency department (ED) with altered sensorium of three hours duration. His relatives mentioned that he had reported of a diffuse throbbing headache for the past last two days prior arrival to the ED and had no symptomatic relief with the over the counter pain medications. He had an episode of nonbilious vomiting on the same day followed by which his sensorium deteriorated. There was no associated fever or seizures or shortness of breath or involuntary micturition. Bystanders denied history of alcohol or smoking or substance abuse.

On arrival, his airway was patent, work of breathing was regular with a respiratory rate of $18 /$ minute with oxygen saturation $(\mathrm{SpO} 2)$ of $98 \%$ in room air, heart rate was 95 per minute, blood pressure was $180 / 120 \mathrm{mmHg}$. He was agitated with a Glasgow coma scale of E2V3M6 and pupil size of $1.5 \mathrm{~mm}$ sluggishly reacting to light bilaterally, with a temperature of $98.6 \mathrm{~F}$.

Random blood glucose was $112 \mathrm{mg} / \mathrm{dl}$. A detailed clinical examination was performed and he was found to have miosis, bilateral hyporeflexia and hypotonia, there was no neck stiffness and rests of the systemic examination were normal. Arterial blood gas analysis showed a $\mathrm{pH}$ of 7.44 , carbon dioxide of $35.2 \mathrm{mmHg}$, lactate of 1.8 . Electrocardiogram (ECG) showed normal 
sinus rhythm with QTC of 444. A Computed tomography (CT) brain scan was done to rule out an intracranial bleed or any other acute pathology which was reported to be normal by the radiologist. His complete blood counts, Renal and liver function tests were within normal limits with sodium of $138 \mathrm{meq} / \mathrm{l}$, urea of $16.3 \mathrm{mg} / \mathrm{dl}$ and Ammonia of $34 \mathrm{mmol} / \mathrm{L}$. Magnetic Resonance Imaging (MRI) brain with contrast was done to rule out leptomeningeal enhancement and posterior reversible encephalopathy syndrome, which was reported as normal by the radiologist. He was treated with short acting beta blockers for hypertensive emergency and was admitted in the Emergency Room Intensive care Unit(ERICU) for further evaluation.

After 3 hours of admission in ERICU, patient had an episode of hypotension with bradycardia with a blood pressure of $80 / 55 \mathrm{mmHg}$ and heart rate of $56 /$ minute, and he was resuscitated with bolus of intravenous fluids. Due to persistent altered sensorium state, history was again cross checked and on further enquiry the patients relatives revealed that he had accidentally ingested clonidine tablet which was used by his son who is a diagnosed case of chronic kidney disease instead of painkillers for his headache.

A nasogastric tube was inserted and gastric samples were taken for toxicology analysis along with blood and urine samples. Toxicology result came positive for Clonidine in blood and urine sample. Patient was placed on continuous hemodynamic and neurological (Glasgow coma scale) monitoring. During the course of next 24 hour stay in ER-ICU, patient clinically and symptomatically improved, regained consciousness and he was obeying commands and taking oral feeds. Hence was shifted out to ward for further medical care and was discharged home within 72 hours.

\section{DISCUSSION}

Clonidine is available as $100,200,300$ microgram tablets and transdermal patches $(2.5,5,7.5 \mathrm{mg})$.
Clonidine acts as a peripheral alpha -2 agonist causing hypertension and also as a central alpha 2 agonist causing reduction in sympathetic outflow thereby causing hypotension, peripheral nitric oxide release, vasodilatation and hypotension. ${ }^{[4,5]}$ It also acts on the opioid receptors there by releasing GABA causing sedation and opioid detoxification, hence a patient presenting with acute clonidine ingestion will have miosis. ${ }^{[6]}$

Peak plasma clonidine concentration occurs at 2 hours of oral or subcutaneous administration. And it reduces blood pressure after 6-8 hours. Whereas the therapeutic effect of clonidine patch last for 26-55 hours. In patients with renal disease the elimination time has been shown to be considerably increased.

Clinical features of clonidine toxicity include hypertension, which might be transient followed by hypotension and bradycardia. Less frequently patients present with agitation, irritability, recurrent seizure or diarrhea. Due to its action on the opioid receptors patient will have miosis, hyporeflexia, hypotonia, respiratory depression, apnea that responds to auditory stimulation, lethargy and coma. Tizanidine can cause QTC prolongation. ${ }^{[7]}$

Gastric decontamination and Activated charcoal are advised if the patient presents in the first one hour of ingestion. There is no specific antidote, naloxone which is a opioid antagonist has a variable response to clonidine poisoning which can be tried if patient has features of respiratory depression and altered sensorium at a dose of $0.1 \mathrm{mg} / \mathrm{kg}$ upto $10 \mathrm{mg}$. ${ }^{[8,9]}$ Every patient with Clonidine toxicity should be admitted in intensive care unit despite of the response to Naloxone.

\section{LABORATORY INVESTIGATIONS}

Random blood sugar check should be the initial investigation done in the ED, to rule out hypoglycemia or hyperglycemia. Blood gas analysis should be done to look for carbon dioxide retention because of respiratory depression. Serum toxicology 
samples should be sent for antihypertensive panel, sedative panel and alcohol panel. Electrocardiogram should be done to rule out QTC prolongation in Tizanidine overdose. [7] Chest X-ray should be mandatorily done rule out features suggestive of aspiration pneumonia. All electrolyte abnormalities should be ruled out and urine pregnancy test should be done in every female of reproductive age group.

\section{MANAGEMENT OF ACUTE CLONIDINE TOXICITY}

Management includes airway and breathing assessment for features of respiratory depression and aspiration and secure the airway if required. All patients should undergo continuous cardiac, hemodynamic, and respiratory monitoring. 12-lead ECG should be done to rule out arrhythmias or heart blocks. All patient require intensive care monitoring for the initial $48 \mathrm{hrs}$. Bradycardia is treated with Atropine $0.6 \mathrm{mg}$ injection every three minutes with a maximum dose of $3 \mathrm{mg} .{ }^{[10]}$ Hypotension can be managed initially by fluids and if there is no response, start Noradrenalin infusion. Hypotension with bradycardia is managed with Dopamine infusion dose of $5-20 \mathrm{mcg} / \mathrm{kg} / \mathrm{minute}$. Hypertension should be treated with shortacting drugs like nitroprusside. If the patient has features of hypothermia, rewarming should be initiated. If the patient is using clonidine patches, it should be removed.

Our patient initially presented to the ED with hypertension, agitation, miosis, hyporeflexia and later manifested hypotension and bradycardia during the course of stay in ER- ICU. Very few studies have documented agitation as clinical presentation of clonidine toxicity. However, features of respiratory depression were absent. Majority of the patients presenting with clonidine overdose, including our case who develop hypotension and bradycardia responds to intravenous fluid administration. ${ }^{[11]}$

The patient and the bystanders were explained regarding the nature of the disease condition and clinical presentation. The need of publishing the clinical information was explained and their verbal and written consent was taken.

\section{CONCLUSION}

Clonidine toxicity is a rare and preventable cause of altered sensorium, miosis, unexplained hypertension and hypotension. Since it is an easily available clinical drug, Emergency physicians should always suspect clonidine toxicity in both children and adults, when presenting with the above manifestations.

\section{DECLARATION OF PATIENT CONSENT}

The authors certify that they have obtained all appropriate patient forms. In the form the patient(s) have/has given his/her/their consent for his/her/their images and other clinical information to be reported in the journal. The patient and bystanders understood that their names and initials will not be published and due efforts will be made to conceal their identity, but anonymity cannot be guaranteed.

Acknowledgement: None

\section{Conflict of Interest: None}

\section{Source of Funding: None}

\section{REFERENCES}

1. Schnoes CJ, Kuhn BR, Workman EF, Ellis $\mathrm{CR}$. Pediatric prescribing practices for clonidine and other pharmacologic agents for children with sleep disturbances. Clin Pediatr (Phila). 2006; 45:229.

2. Lowenstein J. Drugs five years later: clonidine. Ann Intern Med. 1980;92:74.

3. Frisk-Holmberg M, Paalzow L, Edlund PO. Clonidine kinetics in man-evidence for dose dependency and changed pharmacokinetics of clonidine. Clin Pharmacol Ther. 1976; 19:11.

4. Talke PO, Caldwell JE, Richardson CA, Heier T. The effects of clonidine on human digital vasculature. Anesth Analg. 2000; 91:793. 
5. Lowry JA, Brown JT. Significance of the imidazoline receptors in toxicology.Clin Toxicol (Phil). 2014;52:454.

6. Seger DL. Clonidine toxicity revisited. J Toxicol Clin Toxicol. 2002; 40:145.

7. Kaddar N, Vigneault $\mathrm{P}$, Pilote $\mathrm{S}$, et al. Tizanidine (Zanaflex): a muscle relaxant that may prolong the QT interval by blocking Ikr. J Cardiovasc Pharmacol Ther. 2012; 17:102.

8. Farsang C, Kunos G. Naloxone reverses the antihypertensive effect on clonidine. $\mathrm{Br} \mathrm{J}$ Pharmacol. 1979;67:161-164

9. Seger DL, Loden JK. Naloxone reversal of clonidine toxicity; dose, dose, dose. Clin Toxicol .(Phila). 2018; 56:873.
10. Wiley JF 2nd, Wiley CC, Torrey SB, Henretig FM. Clonidine poisoning in young chiildren. J Pediatr. 1990; 116:654.

11. Toubes DB, McIntosh TJ, et al. Hypotensive effects of clonidine and chlorthalidone. Amer Heart J. 1971;82:312318.

How to cite this article: Theresa MM, Arunkumar K, Gireesh Kumar K P et.al. An atypical adult presentation of acute clonidine intoxication. Int J Health Sci Res. 2021; 11(6): 200-203. DOI: https://doi.org/10. 52403/ijhsr.20210632 